\title{
A PERCEPÇÃO DOS PROFISSIONAIS DA SAÚDE FRENTE À EXPOSIÇÃO A RISCOS QUIIMICOS 1
}

\author{
THE HEALTH PROFESSIONALS' PERCEPTION AS TO CHEMICAL RISKS EXPOSURE.
}

\author{
Mônica Aparecida da Silva ${ }^{2}$ \\ Patrícia Bodnar Giuntini ${ }^{2}$ \\ Silvia Helena Meneguin ${ }^{2}$
}

\begin{abstract}
RESUMO: Uma variedade de substâncias tóxicas são expostas todos os dias aos trabalhadores da área da saúde; tais substâncias têm ação nociva sobre os organismos biológicos podendo desencadear quadros de intoxicação. Diante de tal problemática, o estudo realizado objetivou identificar a percepção dos funcionários de uma Central de Material de um hospital de grande porte de Ribeirão Preto - SP, tendo por amostra 12 profissionais/ocupacionais de enfermagem, de ambos os sexos, com faixa etária de 23 a 55 anos. O método utilizado foi entrevistas tipo questionário. Os dados da pesquisa demonstram um desconhecimento dos trabalhadores em questão quanto à relação entre a exposição aos agentes químicos e conseqüentes danos à saúde. Em função desses dados podemos concluir que: (1) os profissionais adotam comportamento de segurança de maneira alienada; (2) encontram-se desmotivados; (3) há falta de interação e autoridade para fiscalização das medidas de controle preventivo; (4) existem falhas no processo de educação continuada. Portanto, compete ao enfermeiro maior responsabilidade no que tange ao desenvolvimento científico, evitando, assim, processos evasivos que geram a não sobrevivência da profissão.
\end{abstract}

UNITERMOS: Enfermagem do trabalho - Riscos químicos - Percepção.

\begin{abstract}
A great variety of substances are exposed to health workers every single day. Such substances have noxious actions on biological organs generating pictures of poisoning. Facing such a problem, this study aimed at identifying the Material Center workers perceptions at a general hospital in Ribeirao Preto, Sao Paulo having 12 nursing professionals/occupationals, both sexes, aging between 23 to 55 years-old, as a sample. The used method was interviews through questionnaires. The data have showed that the workers have no knowledge regarding to the relation between exposure to chemical agents and its consequent health damage. According to these data it has been concluded that: (1) professionals adopt security behavior inadequately; (2) they find themselves demotivated; (3) there is lack of interaction and authority for preventive control measures fiscalization; (4) there are some failures in continued education process. Therefore, its the nurse's major responsibility as for scientific development, so that it can avoid evasive processes that generate profession no survival.
\end{abstract}

KEYWORDS: Labor nursing - Chemical risk - Perception.

\footnotetext{
${ }^{1}$ Trabalho apresentado no $9^{\circ}$ SENPE - Vitória - Espírito Santo, julho de 1997.

${ }^{2}$ Alunas do $4^{\circ}$ ano de Graduação pela Escola de Enfermagem de Ribeirão Preto - USP.
} 


\section{INTRODUÇÃO}

Todos os dias uma variedade de substâncias tóxicas são expostas aos trabalhadores da área da saúde. Em 1991, o Chemical Abstract publicou a existência de cerca de sete milhões de substâncias químicas registradas em nivel mundial. Cerca de sessenta e cinco mil são de uso comum, centenas de uso hospitalar e todas com potencial a riscos. Esterilizantes, solventes, anestésicos, desinfetantes, antisépticos, agentes de limpeza, detergentes e medicamentos diversos são manipulados diariamente pela equipe de enfermagem. Todos são prejudiciais e depende tão somente da dose. E raramente os efeitos produzidos são associados à toxicidade da mesma ${ }^{2}$.

A partir disso, contamos com a toxicologia como sendo a ciência que estuda as ações nocivas dos produtos químicos sobre os organismos biológicos. A intoxicação manifesta-se por um conjunto de sinais e sintomas e pode ser classificada quanto à intensidade dos efeitos (moderada, leve, grave), à duração da exposição (crônica, aguda, subaguda) e ao tipo (locais e sistêmicas).

Os agentes químicos são capazes de produzir todos os tipos de lesão celular e os efeitos da exposição aos mesmos podem manifestar-se tardiamente ou imediatamente. Por exemplo, solventes orgânicos expostos prolongadamente está associado à irritabilidade, fadiga, dor de cabeça, perda de apetite.

O N.I.O.S.H. (National Institute for Occupational Safety and Healt) destaca os seguintes efeitos crônicos causados pela maioria das substâncias químicas:

a. sob a reprodução humana: aborto, natimortalidade, queda de peso ao nascer, mortalidade perinatal, anomalias congênitas, malformações cardiovasculares, alterações na estrutura dos cromossomos;

b. cutâneos: ressecamento, fissuras, dermatites, inclusive foliculite e acne;

c. cancerígenos: atingindo principalmente pulmão, medula óssea, pele, laringe, bexiga, fígado;

d. neurológicos: degeneração dos neurônios.

A interação entre os tóxicos absorvidos simultaneamente pode ser antagônica ou sinérgica.

É importante também considerar que existem fatores que podem modificar e interagir ao organismo quanto as substâncias químicas; são eles:

a. ambientais: temperatura ambiente, pressão atmosférica, ruído, radiação e vibrações;

b. fisiológicos: idade, sexo (suscetibilidade da mulher a hormônios sexuais, gravidez);

c. genéticos: reações de hiposensibilidade e hipersensibilidade;

d. profissionais ou relacionados com o estilo de vida: sobrecarga de trabalho, fadiga, dieta alimentar, estresse, tabagismo ${ }^{2}$.

"No Brasil existem indústrias que possuem um sistema de toxicologia do trabalho de alto nivel." Entretanto, esta não é uma visão global pois somente 
algumas indústrias se conscientizam e fazem uso de um sistema que constam de Centros de Controle de Intoxicações espalhados pelo país. Esses controles objetivam fornecimento de dados para obtenção de um diagnóstico e tratamento de acidentes tóxicos. Vimos através disso que esse não atendimento ao controle de intoxicações desperta o saber da alienação do trabalhador ${ }^{5}$. Rodrigues e Lins, em seu estudo, atentam para fatores sócio, econômico e político que permeiam a atividade do profissional da saúde, bem como a alienação que vivenciam no cotidiano. Há que se ressaltar a crise existencial que permeiam os profissionais da área, que experimentam insatisfação, ansiedade, desestímulo, acomodação por não visualizarem no futuro uma perspectiva de avanço. ${ }^{6}$

O estudo tem como objetivos identificar a percepção dos funcionários da Central de Materiais do Hospital das Clínicas de Ribeirão Preto sobre os Riscos Químicos a que estão expostos.

\section{METODOLOGIA}

O estudo foi realizado na Central de Materiais do Hospital das Clínicas de Ribeirão Preto. O referido hospital foi escolhido para realização deste trabalho por ser parte integrante da Universidade de São Paulo.

A população constou de 65 funcionários profissionais/ocupacionais de enfermagem ( 7 enfermeiras, 49 auxiliares de enfermagem e 9 atendentes de enfermagem), com faixa etária entre 23 e 55 anos.

A amostra constituiu-se de 12 funcionários profissionais/ocupacionais, sendo 7 auxiliares de enfermagem, 4 enfermeiros e 1 atendente de enfermagem, com faixa etária entre 35 e 59 anos.

Foram realizadas 12 entrevistas com formulários elaborados e distribuídos por docentes da disciplina Saúde do Trabalhador. As entrevistas foram feitas por 4 entrevistadores, sendo que o estudo não instituiu treinamento para realização das mesmas. Cada entrevista teve duração média de 30 minutos em todos os turnos, na data de 25 de setembro de 1996.

\section{RESULTADOS OBTIDOS}

Através da análise dos dados obtidos pelas entrevistas, foi possivel identificar que $36,12 \%$ dos profissionais entrevistados negam presença das três formas químicas (gasosa, líquida e sólida) presentes no ambiente de trabalho.

Quanto à concentração de substâncias químicas no ambiente, $41,67 \%$ referiram a sua existência, sendo que o mesmo número de trabalhadores negaram a presença de concentração. Esses dados evidenciam contradição de conhecimentos sobre o assunto e $25 \%$ declararam que não há controle de substâncias, ressaltando que $16,67 \%$ não responderam a questão. 
Em relação ao tempo de exposição, 24,99\% consideram 6 horas diárias, porém constatou-se diversificações de respostas quanto a esta questão.

Pode-se constatar que $58,33 \%$ consideram as vias de inalação como principal porta de entrada para agressores químicos.

Sobre as condições inseguras de trabalho, $33,32 \%$ declaram que não há condições inseguras e que os EPIs são suficientes.

Observando o Quadro 6, verificamos que $41,67 \%$ citaram a inexistência de atos inseguros.

Cerca de $83,33 \%$ afirmaram a interferência do ambiente de trabalho na saúde, porém, $16,67 \%$ atentaram para o contato com o calor e o acondicionamento como meio de interferência.

Em relação aos medicamentos mais utilizados, $41,67 \%$ negam o uso de tais, entretanto $33,33 \%$ não responderam o item e $16,66 \%$ citaram alguns medicamentos. Quanto aos riscos de manuseio e administração, $83,33 \%$ não responderam.

Considerando os cuidados utilizados na administração de drogas e substâncias químicas, $41,67 \%$ citam o uso de luvas e máscaras e $16,67 \%$ trocas de luvas, máscara com filtro especial e óculos, sendo que somente 01 (um) dos entrevistados, correspondendo a $8,33 \%$ do total, não respondeu.

Conclui-se que $33,33 \%$ consideram os problemas respiratórios como principal conseqüência da exposição aos produtos químicos, visto que $16,66 \%$ consideram também os problemas de contato com a pele.

No que tange às outras observações citadas pelo profissionais/ocupacionais, apenas 01 (um) profissional $(8,33 \%)$, enfatizou que os funcionários trabalham em pé e não fazem uso de luvas e máscaras.

\section{DISCUSSÃO}

Visto que as substâncias químicas presentes no ar, água e solo podem acarretar danos à saúde do ser humano, elas são classificadas tanto quantitativamente quanto qualitativamente em todas as atividades produtivas. ${ }^{5}$

Entretanto, para que seja feita uma análise dos riscos químicos de um ambiente, devemos considerar: a concentração do contaminante; o tempo de exposição do trabalhador; as características físico-químicas das substâncias utilizadas, bem como a suscetibilidade pessoal ${ }^{7}$. O uso de EPIs (Equipamentos de Proteção Individual) isentará o trabalhador de danos à saúde. Emil Mrak lembra que "não existem substâncias químicas seguras existem apenas maneiras seguras de utilizá-las"”. 
Entre os diversos critérios de prioridades para situações de risco a agentes químicos pode-se incluir: ausência de estudos toxicológicos; persistência de substâncias no ambiente; aumento de número de pessoas expostas direta ou indiretamente e elevado número de substâncias químicas produzidas a cada ano; possibilidade de biotransformação, biomagnificação e bioacumulação dessas substâncias; dispersão de substâncias nos solos, águas, ar e alimentos ${ }^{5}$.

Conforme a classificação de Bernard e Lawwers (1984), os efeitos dos agentes químicos apresentam quatro fases ${ }^{1}$ :

exposição: significa $\circ$ tempo que $\circ$ indivíduo fica exposto aos componentes, seja na água, no ar e no solo de agentes químicos por diversas vias de absorção (respiratória, cutânea, digestiva e placentária);

toxicocinética: compreende desde que a substância entra no organismo, independentemente da via de entrada, até a distribuição no organismo, transformação, acumulação e eliminação;

toxicodinâmica: é a interação das substâncias químicas com as moléculas do organismo;

clínica: é a exteriorização dos efeitos com aparecimento de sinais e sintomas da intoxicação. O diagnóstico da intoxicação é bem detalhado pois uma substância pode atingir vários órgãos ou um órgão pode ser atingido por uma gama de substâncias.

Dependendo da evolução da intoxicação, os efeitos químicos poderão ser agudos (rápido início e evolução), crônico (início insidioso e de longa duração) e subagudo (quadro intermediário).

Os principais tipos de efeitos causados por poluentes químicos ambientais são: local, quando o efeito se dá no local de penetração no organismo; sistêmica, quando o efeito se dá longe do local de penetração; mutagênico, quando dará alteração no material genético; teratogênico, quando a substância tóxica altera desenvolvimento do feto; carcinogênico, quando a substância tóxica é capaz de induzir a transformação de células normais em células cancerígenas.

Logo, atentando para a nocividade dos agentes químicos e frente aos resultados obtidos, compete-nos descrever algumas das substâncias manipuladas pelos profissionais e ocupacionais em questão:

Óxido de etileno: é utilizado para esterilização dos materiais e estes provocam lesões cutâneas e conjuntivas; além de leucemia, linfoma, neoplasia gástrica e esofágica, disfunções hepáticas e renais, doenças do aparelho circulatório e redução da hemoglobina por degeneração de seus aminoácidos nos individuos. Segundo a Portaria Interministerial $n^{\circ}$. 4, de 31 de julho de 1991, este produto é altamente tóxico, inflamável e explosivo, carcinogênico, mutagênico e teratogênico. Mulher em idade fértil não pode exercer atividades 
relacionadas com a esterilização com este gás. De acordo com esta Portaria é necessário o mínimo de condições para instalação, operação, controle e segurança do ambiente e do processo de esterilização, reesterilização e reprocessamento. Estas visam prevenir danos à produção; ${ }^{9}$

Formaldeido: é utilizado como esterilizante químico; seus efeitos são forte irritação em membranas de mucosas do nariz, boca e olhos causando mal estar. Causa também dermatite, edema ou espasmo da laringe, bronquite obstrutiva e possivelmente edema de pulmão. Foram observados ainda problemas de memória, equilíbrio e sono, alterações do humor e dor de cabeça em mulheres que trabalham em laboratório de histologia com exposição diária ao xyleno e tolueno.

Glutaraldeido: utilizado como esterilizante; possui propriedades esporicidas; efeitos prováveis a saúde: irritação nos olhos; lacrimejamento; rinite; dermatite; dificuldades respiratórias; naúseas e dor de cabeça associados à exposição a $2 \%$ entre o pessoal hospitalar de uma unidade oncológica;

Benzina: a ingestão de benzina pode ocasionar uma sensação de se estar queimando por dentro, ocorrendo vômitos, diarréia e , em casos graves, edema pulmonar. A inalação de vapores concentrados pode ocasionar intoxicação semelhante à do álcool. É altamente perigosa no tocante a incêndios. Quanto à explosão, tem risco moderado quando exposta ao calor e a faísca, devendo, portanto, ser deixada longe.

Entretanto, deve-se considerar os limites de tolerância dessas substâncias químicas no ambiente pois estes limites garantem uma proteção ao trabalhador por serem utilizados como guia para avaliação e controle de riscos contra a saúde ${ }^{7}$. Ressalte-se que deve ser avaliado o tempo de exposição laboral e a intensidade do agente químico.

Então, para se tentar minimizar os danos causados à saúde do trabalhador contamos com medidas de prevenção e controle adotadas, em 1990, na Convenção $n^{\circ} .170$ sobre Produtos Químicos ${ }^{2 ; 7}$. É de competência da empresa a elaboração de fichas informativas detalhadas, no setor de risco contendo informações sobre a classificação dos agentes, seus riscos, medidas de prevenção, procedimentos de emergências, bem como os EPIs necessários para manuseio de tais substâncias. Mais do que todos esses requisitos, torna-se necessário que o trabalhador seja submetido a um treinamento contínuo para que possa estar ciente dos riscos a que está exposto, e assim adquirirá um comportamento que lhe garanta segurança perante os mesmos.

Devemos considerar os riscos aos trabalhadores também em nível ambiental, lembrando que o meio ambiente não é apenas um meio físico biológico mas iguaimente o meio sócio-cultural. 


\section{CONCLUSÃO}

Os dados da pesquisa mostraram que a equipe de enfermagem vem vivenciando um forte dilema no que tange à sua conscientização dos riscos a que estão expostos no trabalho e conseqüências posteriores a estes, também quanto às normas de prevenção e controle de riscos, além de sobressair o Jesconhecimento educativo para a prática laboral.

Há que se ressaltar a contradição das respostas obtidas, visto que a amostra entrevistada nega a existência de agentes químicos porém afirma a interferência destes na saúde, evidenciando um desconhecimento dos trabalhadores em questão. Em contrapartida, podemos avaliar que adotam comportamento de segurança, entretanto de maneira alienada.

Convém salientar que o processo alienatório pode explicitar a inibição da criatividade, a timidez, a insegurança, a frustração e o medo de criar experiências, que são vivenciadas por vários trabalhadores de saúde no desempenho de suas atividades, lembrando que a Enfermagem, com funções bem definidas, pode ser agente provocador de mudanças (SOS). E embasados nisso, fazer-se conhecedores dos direitos para reinvindicá-los quando necessário.

Além disso, podemos destacar que o serviço de segurança e saúde local não é voltada à prevenção, uma vez que isso pode ser atribuído à falta de "vínculos", interação e autoridade para fiscalização ou planejando medidas. de controle preventivo e saúde deparam-se com uma equipe desmotivada ${ }^{3}$.

Entretanto, para uma ampla percepção da equipe de enfermagem é preciso que haja uma reflexão sobre a prática que direciona a realização de pesquisas pelo enfermeiro, o que compromete o "saber" da Enfermagem, tão importante para seu desenvolvimento, enquanto profissão, e para o reconhecimento social do trabalho do enfermeiro ${ }^{10}$. Portanto, compete ao enfermeiro maior responsabilidade no desenvolvimento científico evitando assim um processo evasivo gerando uma não sobrevivência da profissão.

\section{REFERÊNCIAS BIBLIOGRÁFICAS}

1. BERNARD, A. \& LAUWERYS, R. General principles of biologycal monitoring of exposure to organic chemicals. In: A.C.S. Muting. St Louis, 1984.

2. BULHÕES, I. Riscos do Trabalho de Enfermagem: Prevenção $e$ Controle do Risco Químico, Rio de Janeiro: Folha Carioca, 1994. 
3. FARBER, J.H. Onde estamos errando. R. Proteção, n. 43, ano VII, p.49-53, jul. 1995.

4. KURCGANT, P. et al. Percepção dos enfermeiros sobre as atividades que desenvolvem em suas unidades de trabalho. R. EsC. Enferm. USP, v. 27, n. 2 , p. $229-45$, ago., 1993.

5. MENDES, R. Patologia do Trabalho. Rio de Janeiro: Atheneu, 1995.

6. RODRIGUES, E.M.D.; LINS,L.C.S.; Enfermagem no Nordeste: Momento e tendência, $R$. Enferm. Científica, n. 1, ano I, p. 28-31, 1990.

7. SOTO, J.M.O.G; SAAD, I.F.S.D.;FANTAZZINI, M.L.; Riscos Químicos: Avaliação dos Riscos Químicos, São Paulo: Fundacentro, p. 41-44, 1994.

8. UCKO,D.A. Química para as ciências da saúde: Uma introdução à Química Geral, Orgânica e Biológica. Trad. Giglio, J. R. São Paulo: Mamole, 1992.

9. Manuais de Legislação Atlas. Segurança e Medicina do Trabalho. São Paulo: Atlas,1995.

10.

O futuro da enfermagem do trabalho no Brasil. R. S.O.S. da Associação Brasileira para Prévenção de Acidentes. n. 181, p. 7-12, 1995. 